\title{
Nuevas violencias, nuevas voces y nuevas resistencias en tiempos de reorganización hegemónica. Entrevista a Pilar Calveiro
}

New violences, new voices and new resistances in times of hegemonic reorganization. Interview to Pilar Calveiro

JaUme Peris Blanes

UNIVERSITAT DE VALÈNCIA · jaume.peris@uv.es

DOI: $10.7203 /$ KAM.6.7667

ISSN: 2340-1869

Los trabajos de Pilar Calveiro sobre violencia política han venido a reordenar, en las últimas décadas, los debates en torno a la naturaleza de la violencia de Estado, la militancia revolucionaria y las nuevas formas de violencia en el mundo global. Muy pocas investigaciones han tenido, en ese campo, el impacto de las reflexiones de Calveiro ni la capacidad para conectar problemáticas y lógicas aparentemente separadas entre sí para pensarlas de forma vinculada.

En Poder y desaparición (Colihue, 1998) conceptualizó la lógica del poder desaparecedor que se concretó en el sistema de campos de concentración de la última dictadura militar argentina, proponiendo una mirada analítica y un lenguaje novedoso para abordarlo, que redirigeron completamente los debates y estudios sobre las formas de la represión militar. En Política y/o violencia. Una aproximación a la guerrilla de los años 70 (2006) analizó el reverso de la violencia política de esa época describiendo la absorción de lo político por el paradigma bélico y la necesidad de repolitizar las decisiones, las lógicas y las dinámicas adquiridas por cada grupo en ese periodo.

En Redes familiares de sumisión y resistencia (UACM: 2003) y Familia y poder (Libros de la Araucaria: 2006) analizaba las formas de dominación y, sobre todo, de resistencia, en el interior de las estructuras familiares. Tomando a la familia como núcleo fundamental de las relaciones de poder, diseccionaba la forma en que se articulaban las estrategias de confrontación, resistencia, escape y reatrapamiento con las que hombres y mujeres interrelacionan en el campo de fuerzas y poderes que es el espacio familiar. 
En Violencias de estado. La guerra antiterrorista y la guerra contra el crimen como medios de control global (Siglo XXI, 2012) describe las 'reorganizaciones hegemónicas' que tienen lugar desde el mundo bipolar de la Guerra Fría al mundo global del capitalismo avanzado actual y disecciona dos lógicas mayores de la violencia contemporánea: la 'guerra antiterrorista' y la 'guerra contra la delincuencia'. Ese es el punto de partida de esta entrevista, en la que se plantea la posibilidad, estudiada por la autora, de la articulación de alternativas y disidencias a la nueva configuración del poder global y se reflexiona sobre el rol que las escrituras o prácticas testimoniales podrían desempeñar en ellas.

\section{En torno a las violencias contemporáneas}

KАMCHAтKA. En Violencias de Estado describe las 'reorganizaciones hegemónicas' que tienen lugar desde el mundo bipolar de la Guerra Fría al mundo global del capitalismo avanzado actual. En el seno de esas reorganización ¿qué tipo de continuidad y de ruptura se daría entre la lógica de la violencia analizada en Poder y desaparición y las violencias de Estado contemporáneas?

Pilar Calveiro. En Violencias de Estado sostengo que la reorganización hegemónica del mundo, a la que estamos asistiendo, no ha significado una ruptura con los rasgos principales de la Modernidad, sino más bien la profundización de los mismos. La Modernidad nos legó un mundo capitalista, cuya unidad política básica fue el Estado-Nación, con sociedades de clase excluyentes y un fuerte énfasis en la individualidad y la competencia. Por su parte, la globalización neoliberal implica también una economía capitalista pero de alcance verdaderamente mundial, organizada en grandes corporativos y más concentrada aún; el escalamiento de lo estatal a instancias estatales supranacionales, como el Consejo de Seguridad de la ONU, que conviven con los Estados Nación; sociedades estratificadas, fragmentarias y extraordinariamente excluyentes, así como la construcción de subjetividades fuertemente individualistas y replegadas al espacio privado. Así que, si en la era global el capital se concentra, la sociedad se fragmenta y el individualismo se radicaliza, no hay ruptura sino radicalización de la Modernidad.

Hay que decir que la sociedad de masas no es contradictoria con un tipo de individualidad aislante -como ya lo señaló Hannah Arendt. Masa y aislamiento son complementarios. Las sociedades de masas propiciaron un individuo aislado, apolítico y temeroso, incapaz de ejercer la razón crítica. Las sociedades globales neoliberales también han continuado y profundizado este proceso, mundializándolo. Además, en ellas, la biopolítica -que reduce a las personas a sus variables biológicas-, se combina con el abandono más absoluto de enormes grupo poblacionales, cuyas vidas se tratan como irrelevantes.

En Poder y desaparición, yo trataba de analizar una forma específica del poder político en Argentina, que se dio a partir del llamado Proceso de Reorganización Nacional, a través de su dispositivo represivo principal: el campo de concentración. El hecho de designar a los centros clandestinos de 
detención como campos de concentración no fue casual ni tenía un sentido 'efectista'. Por el contrario, consideré que esos centros, en Argentina, reunían los rasgos principales de lo concentracionario, en su dimensión más radical, el campo de concentración-exterminio. En efecto, se trataba de instituciones administradas por el Estado, que servían como lugares de encierro, tortura y eliminación de determinado grupo poblacional, caracterizado como subversivo. Por su funcionamiento, estaban destinadas a desaparecer a las personas, primero en su condición de sujetos políticos y sujetos de derecho, para luego eliminar la condición misma de personas, hasta hacer desaparecer incluso sus restos mortales. Sin embargo, ya entonces advertía algunas diferencias significativas con respecto a otras experiencias concentracionarias, como el aislamiento de los prisioneros entre sí y la completa inactividad a la que se sometía a la mayoría de ellos, como parte del castigo. Más tarde, al estudiar las características actuales de lo concentracionario, llegué a la conclusión de que los campos de concentración en Argentina fueron una suerte de punto intermedio entre el campo de concentración como espacio de hacinamiento, que se vio en la experiencia nazi, y el campo de aislamiento de los prisioneros entre sí y respecto del dispositivo, que se practica en lugares como Guantánamo.

La desaparición forzada, que se utilizó entonces principalmente contra disidentes políticos, no ha cesado en el mundo global, y esto no es casual. En Violencias de Estado analizo la persistencia de la desaparición forzada en el contexto de la llamada guerra antiterrorista. En este caso, tenemos instituciones, también administradas por el Estado, como el centro de reclusión de Guantánamo o los llamados 'sitios negros' de la CIA, donde se perpetúa el proceso de secuestro, desaparición de la persona, borramiento de su condición de sujeto político, arrasamiento de la subjetividad principalmente a través de tortura psicológica y aislamiento radical- y desconocimiento de la responsabilidad del Estado. Sin embargo, ahora esto ocurre a través de redes represivas de carácter global, con centros clandestinos ubicados en distintas partes del globo, intercambio de prisioneros y violación del derecho vigente tanto nacional como internacional e incluso bélico. El dispositivo actual tiene algunas características específicas: es global, combina las formas tradicionales de la tortura con otras que se podrían considerar 'novedosas' y que se basan principalmente en distintas formas de obturación sensorial y tortura psíquica. Por su parte, el aislamiento radical y prolongado es parte central del tratamiento de tortura y desubjetivación de los prisioneros, enfatizando la obstrucción de lo comunicacional como mecanismo de castigo de un poder que, no casualmente, es él mismo fuertemente comunicacional. Estos son simultáneamente campos de concentración y aislamiento de prisioneros. Los concentran allí para aislarlos no solamente del exterior sino incluso entre sí.

Desde luego, hay otras violencias de Estado que no son necesariamente concentracionarias y que ocupan un lugar principal en el mundo actual. Me refiero a los escenarios bélicos que se despliegan y también a las violencias estructurales, no menos importantes, que excluyen a sectores cada vez más importantes de la población. 
KAMCHATKA. En esa reorganización de las violencias de Estado en el capitalismo global, destaca dos grandes modalidades que han sido caracterizadas, de un modo muy significativo, como guerras: la guerra contra el terrorismo y la guerra contra la inseguridad y contra el crimen organizado. ¿Por qué los poderes globales necesitan recurrir a la metáfora bélica para legitimar formas de violencia que no tienen nada que ver, en realidad, con la guerra?

Pilar CALVEIRO. La creación de escenarios bélicos permite ir construyendo la idea de un enemigo especial, un enemigo de la sociedad en su conjunto, que es preciso aniquilar. De esta manera, se convalida que el Estado -que se presenta como el defensor de la población-, frente a una amenaza extraordinaria, recurra a una violencia también extraordinaria. No quiero decir con esto que el terrorismo o el crimen no existieran previamente como fenómeno, sino que se los ha construido en términos bélicos, como guerras con un oponente que es preciso exterminar para proteger a la sociedad. De esta manera se amplían las atribuciones violentas del Estado, se restringen las garantías ciudadanas y se expande el miedo, como dispositivo de control político y social.

Es posible comprobar empíricamente que, tanto la guerra contra el terrorismo como la llamada guerra contra el crimen organizado, no hacen más que agudizar un problema que se va profundizando con el tratamiento bélico; es decir, estas políticas crean aquello que preanuncian. Y lo hacen porque lo necesitan; necesitan enemigos que legitimen su violencia y expandan el miedo. Son 'enemigos' que no deben crecer demasiado pero tampoco es conveniente que desaparezcan.

La 'guerra antiterrorista' crea un enemigo principalmente externo -aunque puede infiltrarse- que habilita, sin más, la ocupación de territorios en cualquier lugar del planeta en el que convenga desplegar fuerzas, por razones políticas, económicas, o de cualquier índole. También justifica las restricciones migratorias, claramente racistas. Por su parte, la "guerra" o lucha contra el narcotráfico, construye enemigos principalmente internos, para legitimar la creación de legislaciones de excepción y la ampliación de las atribuciones violentas del Estado. Estas se dirigen contra los grupos delictivos no controlados, las disidencias políticas y la población en general.

Estas "guerras" generan extraordinarias violencias que son fundamentales en la proliferación del miedo. Tanto en las sociedades centrales, como en las periféricas, se alienta el miedo a unos u otros a través de los discursos oficiales y mediáticos para convalidar políticas cada vez más represivas y atentatorias contra los derechos básicos de expresión, manifestación y disidencia. De hecho, creo que hay que considerar las políticas de proliferación del miedo como uno de los dispositivos característicos de la gubernamentalidad neoliberal. 
KAMCHATKA. Sostiene que la 'guerra contra el terrorismo' sirve, en realidad, para sancionar y aplicar violencia contra casi cualquier forma de oposición al sistema social, económico y político. ¿En qué sentido esta 'guerra' es en realidad una forma de legitimar la violencia contra la disidencia?

Pilar Calveiro. La 'guerra contra el terrorismo' sanciona, en primer lugar, a los países que pueden tener una política no suficientemente alineada con el nuevo orden global, que se dicta desde los poderes supranacionales.

La vaguedad de la definición de terrorismo, adoptada por los organismos internacionales, su caracterización a partir de la intencionalidad de los actos, la inclusión de elementos valorativos, como 'intimidar gravemente' u 'obligar indebidamente' asociadas a la desestabilización de estructuras políticas, constitucionales o económicas de un país, como se sostiene en resoluciones de la Comisión Europea, la hacen apta para su utilización en la represión de las disidencias.

Por otra parte, se han ido imponiendo legislaciones antiterroristas en los distintos países, cuyas redacciones y especificaciones son de una amplitud tal que hacen viable su aplicación en contra de los grupos disidentes internos. Las mismas caracterizan como terrorista distintos tipos de violencia, como los daños u obstrucción de las vías de circulación, medios de comunicación e infraestructura, en los que pueden incluirse formas clásicas de la protesta social como la toma de calles, carreteras o medios de transporte. Aun cuando las legislaciones hagan la salvedad de que no pueden aplicarse en contra de movimientos sociales o políticos, como en el caso de Argentina, la sola existencia de las mismas posibilita que, ante la acción de determinados grupos, aunque tengan fines políticos, se los desconozca y se los criminalice -como suele ocurrir-, para dar cabida a la legislación antiterrorista. El caso de las condenas por terrorismo contra indígenas mapuche en Chile es clarísimo al respecto.

KamchatKa. En los debates sobre la violencia política de los setenta, y en su libro Política y/o violencia, ha defendido la necesidad de no conceptualizar la violencia de los grupos guerrilleros como terrorismo, frente a algunas opciones que sí la abordan en ese sentido. En Violencias de estado insiste en ese razonamiento: los movimientos armados de resistencia no deben ser considerados terroristas porque, en vez crear un terror que inmovilice a la población, buscan su movilización y protesta. ¿Cree que todavía es posible disputar el concepto de terrorismo a los poderes globales e identificar a la 'guerra contra el terrorismo' como la lógica fundamental del terrorismo global, en el sentido que propone darle a ese término? ¿O se trata de una categoría ya tan gastada y llena de ecos y significados discordantes que ha perdido su potencialidad para la elaboración de posiciones de resistencia?

Pilar Calveiro. El terrorismo es, como bien dice, un concepto afín a los poderes globales y, hoy en día, es una categoría que se utiliza para habilitar la excepción, es decir, la suspensión del derecho 
contra aquellos acusados o simplemente sospechosos de terroristas. Es en este sentido que me ha interesado refutar ciertas argumentaciones que califican a las guerrillas de los años setenta de esta manera.

Sin embargo, el uso del terror y el miedo -que no son lo mismo- como instrumentos de control político es un fenómeno importante en nuestro tiempo, al que se debe prestar atención. Por eso me detengo en diferenciarlos. Insisto en que, mientras el miedo es una experiencia inherente a la existencia humana, el terror no. En efecto, el terror inmoviliza pero lo hace porque se acompaña de una violencia masiva, es decir, una violencia muy aguda en sus formas, generalizada, indiscriminada y sostenida por largos periodos. Este tipo de violencia, por sus características, proviene casi invariablemente del Estado o de grupos u organizaciones que están en connivencia con él. En nuestro país ocurrió durante la última dictadura militar, que fue caracterizada adecuadamente como terrorismo de Estado. No es casual que ese Estado, que aplicó el terror contra su población, enarbolara un discurso bélico y acusara de terrorista a la guerrilla. Es lo mismo que hacen hoy los Estados que lideran la lucha que ellos llaman antiterrorista: declaran guerras en las que ejercen una violencia aguda, generalizada, indiscriminada y sostenida contra poblaciones enteras. Es decir, con el argumento de perseguir al terrorismo se han desarrollado las mayores prácticas de terror. Por eso, hay que observar con mucha precaución cualquier acusación de terrorismo y desconfiar del uso de esta categoría, que no es afín a las posiciones de resistencia. En este sentido, sorprende la facilidad con la que cierta izquierda se suma irreflexivamente al discurso del antiterrorismo.

KAMCHATKA. La otra gran modalidad de la violencia que identifica es la 'guerra contra la inseguridad y el crimen'. Si la 'guerra contra el terrorismo' servía para neutralizar mediante la violencia la disidencia política o social de cualquier orden, la 'guerra contra la delincuencia' serviría para neutralizar y procesar a los excluidos que el propio sistema económico y social genera. ¿En qué medida, pues, los discursos securitarios construyen la legitimidad para la creación de espacios de excepción, en el que las personas son excluidas, en cierta medida, del ordenamiento jurídico normal?

Pilar CAlveiro. La 'guerra contra el terrorismo’ sirve principalmente para ocupar territorios de manera impune por parte de las grandes potencias y para desatar políticas de miedo dentro de sus propias poblaciones. La amenaza terrorista, que se mantiene activa con una regularidad sorprendente, permite manejar a las poblaciones por el miedo y hacerlas aceptar la restricción de sus derechos y la ampliación de las violencias estatales, como vemos día a día en Estados Unidos y Europa.

Por su parte, la 'guerra contra la delincuencia' construye un enemigo interno, el delincuente, sobre el que se concentra la multitud de miedos que desatan las distintas violencias (económicas, sociales, mafiosas) del neoliberalismo. Este 'delincuente' no es el que maneja las grandes redes 
criminales, no es el que lava grandes volúmenes de dinero, sino el pibe chorro, el ladroncito, el marginal. Ese es el que va a parar a la cárcel con las políticas de 'tolerancia cero’ que inventa el discurso securitario.

La lógica securitaria coloca en el centro de la agenda política a la seguridad, entendida como un asunto principalmente policial. Reduce lo social, lo económico, lo político, lo cultural a las coordenadas de la seguridad. La delincuencia, la pobreza, la disidencia pasan a ser asuntos de seguridad, que deben ser controlados, no atendidos. Y ese control pasa por adecuaciones jurídicas y punitivas, a cargo de las fuerzas de seguridad.

Así, se crean nuevos tipos jurídicos, se incrementan las penas, se reduce la edad penal y, por lo tanto, aumenta la población penitenciaria, principalmente de varones jóvenes y pobres. También se crea legislación especial en relación con figuras como el ‘crimen organizado’, que restringen las garantías de defensa y los derechos de los procesados bajo esta acusación, es decir, comienza a conformarse una suerte de derecho de excepción o una estratificación o gradación de las garantías jurídicas, donde hay algunos que quedan sencillamente fuera de las mismas.

También hay que decir que, en el neoliberalismo, el Estado de excepción se extiende mucho más allá de este fenómeno. En el mundo actual, grandes sectores de la población quedan, de hecho, fuera del ordenamiento jurídico normal. Es decir, sus propiedades, sus derechos y su vida misma son avasallados sin que el derecho responda por ellos. Es el caso de los migrantes indocumentados, que en América y Europa son objeto de toda clase de abusos sin la menor consecuencia para los perpetradores. En estos casos tenemos Estado de excepción, como también lo tenemos en el caso de la mayor parte de las poblaciones indígenas del continente.

KAMCHATKA. En Violencias de Estado describe la cárcel contemporánea como una ciudad dentro de la ciudad, como una "realidad hologramática con respecto al mundo exterior, aunque con una sobreexposición de la excepcionalidad que en los demás ámbitos de la sociedad existe de manera atenuada”. Por una parte, se señala que la prisión de seguridad media tiene un tratamiento del cuerpo típicamente capitalista. Por otra, la prisión de alta seguridad supone un artefacto de control extremo que reduce al cuerpo a su materialidad biológica. ¿En qué sentido lo que se hace a los presos en el sistema penitenciario reproduce en un espacio concentrado lo que se está haciendo también al conjunto de la sociedad?

Pilar Calveiro. Al observar las prisiones, parto de la idea propuesta por Michel Foucault, de que las prácticas penales se pueden analizar como un capítulo de la anatomía política. En este sentido, lo que vemos dentro de las prisiones corresponde a la la misma anatomía política de las sociedades que las crean y las rodean. Eso no quiere decir que existan relaciones de calca entre ellas pero sí que responden a estructuras y prácticas de poder entramadas y semejantes. 
Creo que el sistema penitenciario constituye un dispositivo que articula las prisiones de seguridad media con las de máxima. De acuerdo con las entrevistas que obtuve, en las de seguridad media, el tratamiento que reciben las personas depende de su capacidad para alimentar el 'negocio' penitenciario, que es verdaderamente muy importante. Como en las cárceles todo se paga -incluso lo que es teóricamente gratuito-, el acceso a la mejor comida, a una cama, al médico, a la visita conyugal, a cierta protección, a tener fuentes de ingreso, está condicionado por las 'aportaciones' que el prisionero pueda hacer al personal penitenciario o a otros reclusos. Por lo mismo, quien tiene los recursos necesarios o entra a los negocios ilegales de la prisión para obtenerlos, puede gozar de cama, comida, sexo y cierta seguridad; quien no, queda librado a su suerte y sus posibilidades de sobrevivir disminuyen.

En las prisiones de seguridad máxima, las necesidades biológicas básicas, como comida, sueño, atención médica, están cubiertas. Sin embargo, el aislamiento radical al que se somete a los prisioneros, al impedirles el contacto con otras personas e incluso con la naturaleza o el aire libre, les arrebata su condición misma de sujeto social, de persona. Se podría decir, en este sentido, que responden a una lógica biopolítica, por la cual la persona se reduce a lo estrictamente biológico y, en tanto material considerado potencialmente peligroso, se la deposita en un lugar confinado, en el que no pueda causar 'daño'.

Considero que también en la sociedad en su conjunto asistimos a procesos de funcionalización de las personas al mercado, como condición de su subsistencia: quienes no pueden articularse satisfactoriamente a las redes monetarias quedan al margen de todo, abandonados a su suerte. Por otra parte, aquellos que tienen resuelto lo estrictamente biológico, son reducidos a esta condición y se les arrebata la condición de sujetos sociales y políticos. Ambas prácticas se articulan y se utilizan de distinta manera sobre diferentes sectores sociales pero todos somos compulsados a garantizar nuestra propia subsistencia, como un asunto individual, a través de recursos monetarios; el acceso a todo, salud, comida, educación, seguridad, es decir a la subsistencia, depende de nuestra capacidad de pagarlos de alguna manera. A su vez, todos somos reducidos de mil maneras a lo biológico-familiar, mientras se intenta replegarnos de los campos social y político.

KamchatKA. En Política y/o violencia señalaba la dificultad de la sociedad actual de pensar la experiencia de las luchas guerrilleras de los setenta desde un horizonte político, y su recurrente desplazamiento a otros paradigmas que la hacían difícilmente comprensible. Algo similar ocurre con las formas y experiencias de la violencia en la contemporaneidad, y el suyo es un trabajo teórico de repolitización de unas violencias que parecieran haber sido expulsadas discursivamente de cualquier dimensión social. ¿A qué dinámicas e intereses favorece esa despolitización de las violencias sociales que su trabajo analítico trata de combatir? 
Pilar CALVEIRO. Siempre ha habido quienes se refieren a la violencia como un asunto propio de la maldad humana, sin más. Sin embargo, la violencia proviene siempre del deseo de imponer o disputar un poder y, en este sentido, también siempre tiene una dimensión política. Por otra parte, hay violencias específicamente políticas, que se ejercen para sostener o modificar el control sobre recursos, territorios, poblaciones, es decir, las estructuras sociales de poder.

Cuando se reúsa la dimensión política de la violencia lo que se hace es oscurecer el problema y dificultar su comprensión. Hoy está suficientemente clara la dimensión política de las violencias de los años 70, tanto las del Estado como las de la insurgencia, aunque haya quienes prefieran focalizarse en otros aspectos del problema.

Sin embargo, no resulta tan clara la dimensión política de las violencias actuales, especialmente las de las grandes redes delictivas. Las mismas se presentan como violencias privadas enfrentadas al poder del Estado; nada más falso que eso. Las violencias de los tráficos ilegales, ya sea de narcóticos, de armas o de personas, están operadas por redes privadas pero sólo pueden tener la dimensión que alcanzan y la impunidad de la que gozan por la protección directa de instancias estatales y políticas, así como por sectores de la economía legal. Digo instancias estatales y no necesariamente el Estado en su conjunto porque el neoliberalismo ha propiciado la fragmentación social así como la fragmentación del Estado. En este sentido, el Estado neoliberal se ha subordinado al poder económico a la vez que ha perdido parte de su centralidad y homogeneidad. Los poderes políticos locales, provinciales o regionales pueden tener una autonomía significativa y aliarse, proteger o consentir el desarrollo de redes mafiosas en su territorio, por razones políticas, económicas y de distinta índole. Lo cierto es que las redes criminales, que se extienden a nivel global, generan grandes flujos de recursos que penetran en la economía formal, vitalizándola, así como en los circuitos políticos, financiándolos y corrompiéndolos. También van de la mano de una reorganización territorial y de la expansión de formas de trabajo prácticamente esclava. Esta articulación de lo legal con lo ilegal y de lo público con lo privado muestra que asistimos a una reorganización de las relaciones de poder que no se puede entender más que políticamente. No estamos frente a una lucha del Estado contra las redes delictivas sino a una articulación de unos y otros, en nuevas formas de acumulación y concentración de la riqueza. Las violencias principales provienen de las luchas por el control de territorios de diferentes grupos, en el seno de los cuales se hallan actores estatales y privados que se apoyan mutuamente; esta articulación es orgánica. Eso no quiere decir que no existan también, ciertas instancias estatales que se mantengan al margen de tales alianzas y busquen, más que la eliminación, el control de las redes mafiosas, para una mayor gobernabilidad. Pero, como bien señala el periodista de La Jornada, Julio Hernández López, en lugar de hablar de la delincuencia organizada deberíamos hablar de la delincuencia políticamente organizada. 
KAMCHATKA. Los dos grandes grupos que, en su razonamiento, sufren las nuevas modalidades de las violencias de estado son los disidentes y los excluidos. ¿Es posible imaginar un espacio de construcción política en el que ambas categorías entren en contacto? Dicho en términos más esquemáticos, ¿se trata de dos categorías aisladas una de la otra o que tienen puntos de contacto?, ¿sería posible una especie de alianza entre disidentes y excluidos para articular formas de nuevas de resistencia frente a las lógicas del poder global?

Pilar Calveiro. No puedo pensar la disidencia al margen de la exclusión. Toda disidencia proviene de una exclusión que reclama, en primera instancia, por sí misma. Pero las disidencias se amplían y se conectan para denunciar y resistir las distintas exclusiones de un orden al que consideran injusto. Sin embargo, la condición de excluido no necesariamente se acompaña de la condición de sujeto activo de la disidencia.

Creo que las poblaciones que sufren la mayor exclusión en el mundo actual son los indígenas y los migrantes indocumentados. Aunque todos ellos viven las peores violencias del mundo actual, sus condiciones materiales de existencia son muy diferentes y hacen que sus posibilidades y formas de resistencia sean muy distintas. Las personas que se ven obligadas a una migración forzada -ya sea por guerras, violencias mafiosas o condiciones económicas-, resisten caminando, pasando a pesar de todo, empujando en las fronteras. Su resistencia es moverse, esconderse y pasar, a la vez que se apoyan en ciertas formas de organización propia, en escasas redes solidarias y en recursos legales que se les niegan sistemáticamente. Mientras están moviéndose, la organización es muy precaria y la disidencia se expresa principalmente a través de organismos de solidaridad de no migrantes o ex migrantes.

Las comunidades indígenas, por el contrario, cuentan con el tejido comunitario, que provee de antiguos lazos sociales y culturales. Resisten defendiendo su territorio, asentándose en él y disputando a quienes pretenden desplazarlos, justamente para no convertirse en migrantes forzados. Tienen, por lo mismo, mayor posibilidad de construir organizaciones propias y de participar en los movimientos de disidencia política, pero sus luchas no se contraponen con las de otros grupos sociales ni con las redes de apoyo de los migrantes. Por el contrario, en muchos casos estas se asientan en contextos comunitarios, de los que proviene también la migración.

Todo excluido es potencialmente disidente, pero sólo potencialmente. El gran asunto político, en sociedades cada vez más excluyentes, es cómo pensar, potenciar y articular las disidencias, de manera que sean lo suficientemente poderosas para construir un mundo en el que, de verdad, quepamos todos.

KАMCHATKA. Estas nuevas formas de violencia han arrasado con buena parte de las identidades colectivas y populares, atomizando y disgregando a los actores críticos y sometiéndolos a cargas de violencia tal que han conseguido destruir los elementos en torno a los que se articulaban sus identidades 
colectivas y políticas. Sin embargo, se puede observar también el surgimiento de nuevas lógicas de comunidad, y autogobierno, especialmente en colectivos indígenas, que tienen un modo muy diferente de abordar y resistir las lógicas de los poderes globales. ¿Cómo funcionan, en rasgos generales, estas nuevas lógicas comunitarias que contradicen esa aparente caída de los proyectos colectivos? ¿Qué efectos tienen esas nuevas lógicas en la subjetividad de sus integrantes y en su percepción de sus opciones de vida?

Pilar Calveiro. Desde una primera mirada, puede dar la impresión de que las resistencias locales son insignificantes, sobre todo en el contexto de poderes tan gigantescos como los que controlan la actual globalización. Sin embargo, y a pesar de las tecnologías que pretenden ver todo y controlar todo, hay que decir que cuanto más global es un poder mayor es también el espacio de su incertidumbre, de sus zonas de ambivalencia y de sus puntos y líneas de fuga, de sus fisuras. El gigantismo del poder se expresa en todos los niveles pero lo global, lo regional, lo nacional y lo local no se replican mecánicamente; cada uno tiene sus especificidades, y también su potencia. No es casual que, en el contexto de la globalización, las comunidades indígenas hayan tenido una importante capacidad de resistencia en relación con los Estados nación excluyentes y también en relación con algunas grandes corporaciones transnacionales, como las mineras.

Las comunidades indígenas de México han mantenido el tejido social y cultural de una manera más consistente que otros sectores de la sociedad. Después de siglos de devastación, sin embargo mantienen una identidad propia, anclada en la cosmovisión prehispánica. Lo comunitario por sobre lo individual y la inseparabilidad entre la naturaleza, la sociedad y lo sagrado, que se conjugan en la noción de territorio, son parte sustantiva de esa cosmovisión. Al mismo tiempo, no han quedado ancladas en un pasado ancestral sino que han vivido fuertes procesos de actualización, mestizajes de distintos tipo y resistencias variadísimas. Aunque excluidas del poder político en el mundo mestizo, se han movido en él, lo conocen y no le temen. Por el contrario, su resistencia se ha sostenido a lo largo de siglos y ha consistido fundamentalmente en construir alternativas propias, desde los márgenes del Estado. Lo han hecho de distintas maneras y no necesariamente enfrentándose con el Estado, pero sí desconfiando de su palabra y tratando de no depender de sus recursos. Los procesos autonómicos tienen distintas características; no corresponden a un mismo modelo. Sin embargo, todos persiguen el control del propio territorio en un sentido amplio, que abarca la toma de decisiones políticas, económicas y culturales dentro del mismo.

Creo que el hecho de contar con redes sociales más consistentes les permite comprender y visibilizar más claramente los procesos de desposesión a los que se trata de someterlas, y actuar en consecuencia. A su vez, el doble manejo de una cosmovisión no capitalista, junto al conocimiento de los presupuestos y dinámicas propiamente capitalistas y neoliberales, les permite crear nuevas alternativas y construir procesos de resistencia novedosos y exitosos. 


\section{En torno al testimonio de esas violencias}

KAMCHATKA. No hay duda de que las representaciones de la violencia juegan un papel de enorme relevancia en la legitimación o deslegitimación de esas formas novedosas de violencia en el mundo actual. En ese sentido, el testimonio de la violencia puede tener también un doble rol y una doble funcionalidad con respecto a ellas. Por una parte, puede contribuir, cuando se centra en el sufrimiento causado por las violencias sociales (la delincuencia menor o la violencia urbana...), a un sobredimensionamiento cultural que legitime implícitamente las lógicas de guerra con las que los poderes estatales enfocan los problemas sociales. Por otra parte, cuando se centra en la propia violencia perpretada por los mecanismos del estado, puede contribuir a desnaturalizar, extrañar y deslegitimar las violencias de estado y las nuevas formas de represión. Como tendencia general, los medios de comunicación masivos dan mucha mayor cobertura a la primera tendencia testimonial que a la segunda. ¿Cuáles pueden ser, pues, los espacios posibles para un uso crítico del testimonio de las violencias contemporáneas, que contribuya a deslegitimar las violencias represivas y no a legitimarlas?

Pilar Calveiro. En primer lugar, creo que hablar de 'el testimonio', en términos generales, no es de mayor utilidad. Es necesario precisar: testimonio de qué y de quién y, sobre todo, para qué. Y no es que haya palabras que valgan más o menos que otras, sino que hay palabras más o menos pertinentes en relación con cada problema. Hay que saber de qué quiero hablar cuando lo hago con otros, a través de otros, es decir, con el testimonio de otros.

La recuperación del testimonio, como la recuperación de los documentos históricos -ni más ni menos- no es neutral, se hace desde cierta intencionalidad. En mi caso, uso el testimonio en todos mis trabajos desde una posición política contraestatal, de denuncia de lo represivo y la violación de derechos por parte de de las agencias gubernamentales. Los medios de comunicación hegemónicos hacen exactamente lo contrario y por lo tanto recurren a testimonios que exaltan el resentimiento para justificar la violencia estatal.

Creo que las generalizaciones sobre 'el testimonio', 'la víctima', 'la violencia' son estratagemas discursivas que generan confusión. Todas esas categorías requieren de precisiones. No hay violencia; hay violencias, distintas por sus formas, por sus destinatarios y por sus ejecutores; si no se precisan estos ejes hablamos en el aire. No existe 'la víctima' o, en otras palabras, todos somos víctimas de algo y, por lo tanto decir 'la víctima' es lo mismo que nada; hay que establecer víctimas de qué, de qué violencias en concreto. Por fin, lo mismo con respecto al testimonio: antes de teorizar sobre 'el testimonio' hay que precisar de que testimonio hablo y para qué tomo ese o esos testimonios.

Yo he usado, en Poder y desaparición, el testimonio de víctimas del terrorismo de Estado, para mostrar, con su palabra, cómo operaba este dispositivo concentracionario en Argentina, sobre el cuerpo 
de las personas. ¿Desde dónde lo hice? Desde la perspectiva de esas víctimas, no desde la perspectiva de los perpetradores. Este otro relato y estos otros testimonios posibles, podrían ser parte de otro análisis, pero no eran parte de lo que yo buscaba. Nunca se arma el relato completo; siempre es un relato, no EL relato. Por ejemplo, cuando Claude Lanzman, en Shoah, entrevista a sobrevivientes judíos de los campos de concentración, pero también a algunos jerarcas nazis, no lo hace con una intención de 'objetividad' o de un 'relato completo' sino para desnudar el prejuicio, la violencia y la insensibilidad de los nazis.

En mi caso, me interesan los testimonios que muestran las formas de ejercicio del poder sobre los cuerpos, cómo proceden y cómo se resisten, porque creo que ello da cuenta de las características de ese poder, de sus potencias y de sus limitaciones. Por eso he entrevistado a mujeres y hombres en las relaciones familiares de poder, a prisioneros dentro de las instituciones penitenciarias y, más recientemente, a miembros de comunidades indígenas en resistencia. Sus testimonios nos permiten escuchar las voces excluidas, silenciadas pero también, y sobre todo, aprender de ellas.

KamchatKa. Su libro Poder y desaparición está escrito desde una compleja posición analíticotestimonial en la que la capacidad para el análisis histórico, sociológico y teórico de las modalidades de la represión se cruza con la presencia muy puntual de marcas que indican una pertenencia personal al universo que se está analizando. ¿Se trataba de una precaución ante excesos del yo testimonial, como se ha llegado a analizar, o de la articulación de una posición intersticial entre lo analítico y lo experiencial?

Pilar Calveiro. Creo que el testigo siempre cruza lo experiencial con lo analítico. No hay testimonio que no contenga algún tipo de interpretación, es decir, de análisis. Desde luego que hay una intención analítica en Poder y desaparición y en todo mi trabajo, a partir del material testimonial. También creo que en el acto de testimoniar se juega una cierta ética del testigo. ¿A qué me refiero con esto? El testigo tiene que ser, desde luego, fiel a su experiencia; su fidelidad pasa por no alterar la vivencia que es, siempre, información precisa, junto a una interpretación de lo vivido, una asignación de sentido que ocurre incluso por la organización del relato. Pero la ética, desde mi punto de vista, también exige que el testimonio no se quede en la transmisión del puro dolor. Su desafío más importante es tratar de hacer socialmente transmisible la experiencia, es decir, reconocer al Otro que escucha como sujeto pleno, capaz de comprender, recoger y movilizar lo que se transmite según sus propias necesidades y coordenadas de sentido. Para que la experiencia sea efectivamente transmisible es necesario que quien la escucha pueda hacer algo con ella; pueda pasar más allá de la empatía con el dolor de la víctima, entender lo que se está relatando y hacerlo útil, relevante, significativo para el presente. Esta es una responsabilidad compartida entre quien realiza el testimonio y quien lo recibe. Sin este doble compromiso, el testimonio puede ser irrelevante o incluso contraproducente para las prácticas sociales de resistencia. 
KAMCHATKA. En la segunda parte de Violencias de Estado analiza testimonios de ex-presos mexicanos para describir las lógicas del sistema carcelario actual. Por el uso que hace de ellos, aunque aludan a experiencias personales parecen construir el relato de una experiencia colectiva. ¿Como enfrenta en sus trabajos esa tensión entre la enunciación individual del testimonio y el carácter común de su experiencia?

Pilar Calveiro. Experiencias como la prisión o la desaparición forzada son de carácter eminentemente social, es decir, colectivo. No sólo se viven con otros sino que también se significan con otros. En este sentido, los relatos de los presos de cárceles mexicanas refieren experiencias que, siendo individuales, traspasan esa frontera. Cada una da cuenta, en carne y hueso, de algo más que la vivencia de su carne y de su hueso. Una persona atada a una reja para poder dormir parada, una mujer intervenida quirúrgicamente sin anestesia, un hombre encerrado en una celda de hormigón y escuchando a lo lejos los sonidos de las voces humanas que no lo interpelan me permiten 'tocar', de alguna manera, su propia vivencia y, con ella, el universo del encierro. No son un asunto de Juan o María; son un asunto que traspasa su individualidad, y también son un asunto nuestro, sociólogos, politólogos, activistas o lo que sea... personas. Es algo que nos concierne y que reclama nuestra respuesta. Nos habla de experiencias de muchos pero, sobre todo, de prácticas sociales en las que estamos involucrados de distinta manera. Hay que preguntarnos, como proponía Susan Sontag, en qué medida nuestros privilegios descansan sobre esos infortunios. En síntesis: el testimonio, siendo individual, habla más que de la propia experiencia; el testigo siempre habla por sí y por otros. Es función de quien trabaja con testimonios identificar el armazón social y político del relato. Por otra parte, el testimonio no sólo cuenta, al hacerlo interpela la responsabilidad de quien escucha. Y también ahí se toca la enunciación individual con la experiencia común y, en especial, con la responsabilidad común sobre esa experiencia.

KAMCHATKA. La escritora Belén Gopegui señalaba en una entrevista en esta misma revista que una de las dificultades más importantes de la cultura crítica de izquierdas en la actualidad consiste en ‘afirmar un antagonismo victorioso’. Aludía de esta forma a la dificultad de generar imágenes, relatos y marcos de sentido en los que sean visibles la construcción de otro mundo posible, fuera de las lógicas del capitalismo global, así como la dificultad para representar una resistencia victoriosa frente a sus poderes. En ese sentido, ¿qué función podrían tener los testimonios y relatos culturales de las resistencias a las formas contemporáneas de la violencia?, ¿qué rol podrían desempeñar, por ejemplo, los testimonios y relatos del funcionamiento de esas nuevas lógicas comunitarias que producen realidad nuevas y nuevas formas de subjetividad que son desconocidas prácticamente por la ciudadanía global? 
Pilar Calveiro. Las resistencias a las formas contemporáneas de la violencia y el miedo son prueba de que hay muchos a los que este mundo no les gusta y que, potencialmente, otro mundo es deseable pero también posible. En este sentido, las resistencias comunitarias en particular, juegan un papel de gran importancia por su consistencia y por las alternativas que proponen. No representan el regreso a un mundo mítico y arcaico sino la posibilidad de novedosas articulaciones entre las visiones comunitarias tradicionales y la política actual. Ahora bien, un académico puede estudiar las características del entramado comunitario, su historia, sus dinámicas, sus prácticas pero es el testimonio, la palabra directa de los miembros de la comunidad, la que nos da acceso a lo cotidiano, a sus representaciones, a las formas de asignación de sentido que articulan esas prácticas. El testimonio nos permite acercarnos a ellas, para aprender. En efecto, cuando se trata de otras formas de entender las relaciones sociales, el vínculo con la naturaleza y la dimensión de lo sagrado, escuchar es la primer puerta para abrir la cabeza y el corazón. Escuchar, sentir, pensar; cada uno de estos actos tiene su momento y su importancia.

Frente a una ciudadanía en la que el sujeto es el individuo racional y crítico, lo comunitario puede agregar elementos fincados en la construcción y potenciación de un sujeto colectivo que no disuelve pero sí contiene lo individual. En relación con la contraposición cultura-naturaleza del modelo occidental, el vínculo consustancial entre naturaleza, cultura y sociedad puede abrir otras formas de relación entre nosotros y con aquello que aparece como nuestro entorno pero que nos constituye radicalmente. Por fin, la idea de una sociedad corresponsable de las transgresiones de sus miembros, cuestiona nuestros instrumentos de justicia punitiva y les opone la propuesta de una justicia compensatoria, del todo diferente. Estas alternativas no ofrecen respuestas definitivas sino apenas alternativas, pero esa es su mayor virtud: abrir la posibilidad de abordar los problemas actuales de otras maneras. Dice Boaventura de Souza que todas las culturas tienen puntos ciegos y de lo que se trata es de la posibilidad de diálogo y traducción entre unas y otras. Abrirnos a las experiencias comunitarias nos permite conocer otras formas de resolver problemas tan centrales como el equilibrio con la naturaleza, la seguridad colectiva o la administración de justicia. Y, una vez más, el testimonio puede ser una pieza clave para ir más allá de las prácticas y comprender sus sentidos, es decir, para facilitar la transmisión de experiencias distintas, para abrir el diálogo y realizar las traducciones necesarias. 